\title{
Effect of Maternal Depression on Brain-derived Neurotrophic Factor Levels in Fetal Cord Blood
}

\author{
Erdem Onder Sonmez ${ }^{1}$, Faruk Uguz ${ }^{2}$, Mine Sahingoz ${ }^{2}$, Gulsum Sonmez ${ }^{3}$, Nazmiye Kaya ${ }^{2}$, \\ Mehmet Akif Camkurt', Zeynel Gokmen ${ }^{5}$, Mustafa Basaran ${ }^{6}$, Kazim Gezginc $^{7}$, Sami Sait Erdem ${ }^{8}$, \\ Hasan Haluk Dulger', Erkan Tasyurek \\ ${ }^{1}$ Department of Psychiatry, Dr. Ekrem Tok Mental Health and Disease Hospital, Adana, ${ }^{2}$ Department of Psychiatry, ${ }^{7}$ Department of Obstetrics \\ and Gynecology, ${ }^{9}$ Department of Biochemistry, Meram Faculty of Medicine, Necmettin Erbakan University, Konya, ${ }^{3}$ Department of Pediatrics, \\ Çukurova University, Adana, ${ }^{4}$ Department of Psychiatry, Afşin State Hospital, Kahramanmaras, ${ }^{5}$ Department of Neonatology, ${ }^{6}$ Department of \\ Obstetrics and Gynecology, ${ }^{8}$ Department of Biochemistry, Konya Research and Training Hospital, Konya, Turkey
}

\begin{abstract}
Objective: We aimed to assess the association between cord blood brain-derived neurotrophic factor (BDNF) concentration and maternal depression during pregnancy.

Methods: A total of 48 pregnant women, admitted for elective caesarean section to Department of Obstetrics and Gynecology, The Konya Research and Training Hospital and Konya Necmettin Erbakan University Meram Medical Faculty, were included in this study. The study group included 23 women diagnosed as having depression during pregnancy and the control group included 25 pregnant women who did not experience depression during pregnancy. Results: The groups had similar sociodemographic characteristics. Cord blood BDNF concentration was significantly lower in babies born to mothers with major depression as compared with those in the control group. We didn't find any correlation between the umbilical cord blood BDNF levels and BDI scores.

Conclusion: The results suggest that the existence of major depression in pregnant women may negatively affect fetal circulating BDNF levels.
\end{abstract}

KEY WORDS: Brain-derived neurotrophic factor; Pregnancy; Depression; Fetal cord blood; Neurodevelopment.

\section{INTRODUCTION}

Depression, which is approximately twice as frequent in women than men, is an important psychiatric condition during pregnancy. ${ }^{1)}$ Frequency of major depression in pregnant women was reported to be in between $3-6.6 \% .^{2-4)}$ Maternal depression during pregnancy is an important condition because potential adverse effects on the fetal development. ${ }^{5)}$ Several studies investigated the effects of maternal depression on birth outcomes. Although there is no clear consensus as yet, according to conclusions of these studies pregnancy depression seems

Received: April 12, 2016/Revised: May 27, 2016

Accepted: June 16, 2016

Address for correspondence: Erdem Onder Sonmez, MD Department of Psychiatry, Dr. Ekrem Tok Mental Health and Disease Hospital, Adana 01500, Turkey

Tel: +90-505-3834585, Fax: +90-344-5112966

E-mail: eondersonmez@gmail.com

ORCID: https://orcid.org/0000-0002-1647-6287 to be associated with low birth weight and shorter duration of pregnancy. ${ }^{7-10)}$

Neuroplasticity is a novel hypothesis in the etiology of depression. Brain derived neurotrophic factor (BDNF) is the main neurotrophic factor that is responsible for brain neuroplasticity and neurodevelopment. ${ }^{11)}$ BDNF is responsible from the production, growth and differentiation of immature neurons during the developmental stage of brain, important for survival of neurons. BDNF enhances the development of noradrenergic and serotonergic neurons, increasing their life span by preventing them from toxic damage. ${ }^{12)}$ Furthermore, it is effective in neurogenesis and synaptic plasticity. ${ }^{13)}$ Administration of exogenous BDNF was found to increase complexity and dendrite length of pyramidal neurons in visual cortex development. ${ }^{14)}$ With suppression of BDNF gene, neuroplasticity detoriates, neurons become more vulnerable to distress, easily initiate apoptosis and as a result atrophy occurs. $^{15,16)}$

(ㄷ) This is an Open-Access article distributed under the terms of the Creative Commons Attribution Non-Commercial License (http://creativecommons.org/licenses/by-nc/4.0) which permits unrestricted non-commercial use, distribution, and reproduction in any medium, provided the original work is properly cited. 
Proper fetal brain development requires appropriate combination of both genetic and environmental factors. While intrauterine environment breaks down, this may result in disturbances in fetal brain development which may be critical for neuro-psychiatric disorders. ${ }^{17)}$ As mentioned above, BDNF is critical for appropriate neuronal development. Previous data denote that disruption of BDNF during fetal phase causes more depressive behaviours in mice than post-natal disruption. ${ }^{18)}$ As far as we know, intrauterine BDNF is critical for neurodevelopment and it's shown that BDNF in maternal blood crosses the placenta. ${ }^{19)}$ Likewise in another study, Chouthai et al. ${ }^{20)}$ revealed that the amount of BDNF in the umbilical cord may reflect the amount of central nervous system BDNF level, because of the fact that the blood-brain barrier has not developed at the intrauterine phase of brain development. Circulating BDNF was reported to be correlated with BDNF in the brain in a study on rats. ${ }^{21)}$

To date, few studies evaluated fetal cord blood in terms of maternal psychiatric diagnosis. Maternal generalized anxiety disorder found to be associated with decreased BDNF levels in fetal cord blood but obsessive compulsive disorder was associated with increased tumor necrosis alpha levels. ${ }^{22,23)}$ Oxidative stress takes an important part in the aetiology of psychiatric disorders. ${ }^{24-26)}$ Total antioxidant status, total oxidant status, malondialdehyde, superoxide dismutase and catalase levels were similar in depressed patients; however, glutathione peroxidase activity was significantly decreased. ${ }^{1,5,27)}$

Infants exposed to maternal stress and depression, were reported to experience behavioral, cognitive and emotional problems more frequently in the childhood, but the exact biological mechanism responsible from these problems is unknown. ${ }^{28-30)}$ Depending on previous knowledge about this topic, in the present study, we hyphthesized that fetal cord BDNF levels is lower in depressed mothers and aimed to compare BDNF levels of fetal cord blood collected from umbilical vein of depressed mothers with healthy mothers.

\section{METHODS}

\section{Subjects}

This study was carried out in women giving birth by elective caesarean section at the Obstetric Clinic of Konya Research and Training Hospital in Konya, Turkey, and the
Obstetric Clinic of Meram Faculty of Medicine of Necmettin Erbakan University in Konya, Turkey, at the same time as our two previous studies. ${ }^{22,23)}$ The methodology of the current study was also similar to the others.

The study sample included 23 women with a diagnosis of major depression alone according to the Diagnostic and Statistical Manual of Mental Disorders, fourth edition (DSM-IV) and 25 women without any psychiatric diagnosis (controls) who met the study criteria and who gave birth at these two clinics. Reasons for choosing caesarean section were, collection of blood samples by a pediatrician, similar birth duration, exclusion of birth complications. The inclusion criteria for the study as follows: voluntary participation to the study and current age between 18-40 years. Patients with a history of medical illnesses (e.g., endocrine abnormalities, cardiovascular and pulmonary system diseases, neurological disease, and metabolic disease), a history of pregnancy related complications (e.g, gestational hypertension, imminent abortion, placenta previa and other placental abnormalities, vaginal bleeding, and gestational diabetes), any malformation in newborn infants, a history of maternal infection which can affect fetal growth, any active maternal infections, mental retardation, multiple pregnancies, intrauterine growth restriction, low birth weight, preterm delivery or emergency caesarean section, a history of psychotic disorders, those who reported smoking or alcohol consumption during pregnancy, who had used systemic corticosteroids during pregnancy such as betamethasone dipropionate, those that had used any psychotropic medications during pregnancy, and those in whose infants hypoxia had developed during delivery were excluded.

\section{Assessments}

The sociodemographic and obstetric characteristics were recorded with a semistructured interview form developed by the authors. The diagnosis of major depression and screening for other psychiatric disorders were performed by means of the Structured Clinical Interview for DSM-IV (SCID-I). ${ }^{31)}$ The gestational age at delivery was calculated on the basis of the date of last menstruation. The indication or plan of elective caesarean section was independent from the study procedure. Depression symptom levels were assessed with the Beck Depression Inventory (BDI). ${ }^{32)}$ 


\section{Procedures}

The study procedure was approved by the ethics committee of Meram Faculty of Medicine of Necmettin Erbakan University (2010/146). Initially, the objectives and procedures of the study were explained to all participants, and written informed consent forms were obtained. After the sociodemographic and obstetric features of the participants hospitalized for elective caesarean section were recorded, a psychiatric interview by means of SCID-I was carried out by psychiatrists with at least 4 years of experience on psychiatric disorders and the diagnostic instruments. During the caesarean section, a blood sample for BDNF analysis was obtained from the umbilical vein by a pediatry specialist. The blood was immediately centrifuged for 10 minutes at $3,000 \times g$ and $4^{\circ} \mathrm{C}$. The serum was stored at $-80^{\circ} \mathrm{C}$ until measured. Serum BDNF concentrations were determined by enzymelinked immunosorbent assay (ELISA), according to the manufacturer's instructions (RayBiotech, Inc., Norcross,

\section{Statistical Analysis}

The data were analyzed using the Statistical Package for the Social Sciences (SPSS) version 16.0, for Windows (SPSS Inc., Chicago, IL, USA). All variables were tested with the Kolmogorov-Smirnov test to determine whether the distributions were normal or not. Categorical variables among the study groups were compared using the chi-square test or Fisher's exact test when necessary. Comparisons for continuous variables were performed using Student's $t$ test for normally distributed variables or Mann-Whitney $U$ test for non-parametric variables. All significant levels were 2-tailed and set at the level of 0.05. Correlations between BDNF levels and other variables were analyzed with Spearman's correlation test (for nonnormally distributed variables) and Pearson's correlation test (for normally distributed variables).

Table 1. Sociodemographic characteristics and obstetric data of the patients

\begin{tabular}{|c|c|c|c|}
\hline Characteristic & $\begin{array}{l}\text { Mothers with a diagnosis } \\
\text { of depression }(n=23)\end{array}$ & $\begin{array}{l}\text { Mothers without a diagnosis } \\
\text { of depression }(n=25)\end{array}$ & $p$ value \\
\hline Age $(y r)$ & $29.43 \pm 5.02$ & $28.48 \pm 6.82$ & 0.586 \\
\hline \multicolumn{4}{|l|}{ Marital status } \\
\hline Widow/divorced & $1(4.3)$ & $0(0)$ & \multirow[t]{2}{*}{1.000} \\
\hline Married & $22(95.7)$ & 25 (100) & \\
\hline \multicolumn{4}{|l|}{ Education level } \\
\hline Primary & $12(52.2)$ & $19(76.0)$ & \multirow{3}{*}{0.203} \\
\hline High school & $6(26.1)$ & $4(16.0)$ & \\
\hline College & $5(21.7)$ & $2(8.0)$ & \\
\hline \multicolumn{4}{|l|}{ Yearly income } \\
\hline Low & $12(52.2)$ & $9(36.0)$ & \multirow{3}{*}{0.525} \\
\hline Medium & $8(34.8)$ & $12(48.0)$ & \\
\hline High & $3(13.0)$ & $4(16.0)$ & \\
\hline Children & $2.04 \pm 0.93$ & $1.92 \pm 0.91$ & 0.543 \\
\hline \multicolumn{4}{|l|}{ History of miscarriage } \\
\hline Negative & $17(73.9)$ & $18(72.0)$ & \multirow[t]{2}{*}{1.000} \\
\hline Positive & $6(26.1)$ & $7(28.0)$ & \\
\hline \multicolumn{4}{|l|}{ First delivery } \\
\hline Yes & $19(82.6)$ & $20(80.0)$ & \multirow[t]{2}{*}{1.000} \\
\hline No & $4(17.4)$ & $5(20.0)$ & \\
\hline \multicolumn{4}{|l|}{ Type of anesthesia } \\
\hline Epidural & $14(60.9)$ & $13(52.0)$ & \multirow[t]{2}{*}{0.573} \\
\hline General & $9(39.1)$ & $12(48.0)$ & \\
\hline \multicolumn{4}{|l|}{ Infant gender } \\
\hline Male & $13(56.5)$ & $13(52.0)$ & \multirow[t]{2}{*}{0.78} \\
\hline Female & $10(43.5)$ & $12(48.0)$ & \\
\hline Umbilical cord BDNF level (ng/ml) & $0.98 \pm 0.45$ & $2.08 \pm 0.91$ & 0.000 \\
\hline
\end{tabular}

Values are presented as mean \pm standard deviation or number (\%). BDNF, brain derived neurotrophic factor. 


\section{RESULTS}

\section{Demographic and Obstetric Data}

The mean age of mothers included in this study was $28.94 \pm 5.98$ years. Forty seven (97.9\%) were married, and one mother $(2.1 \%)$ was a widow/divorced. Thirty one $(64.6 \%)$ of the mothers had an elementary school education level while $10(20.8 \%)$ were high school graduates and 7 (14.6\%) were college graduates. Thirteen (27.1\%) mothers had a history of abortion. Nine mothers were giving birth for the first time (18.8\%). Twenty one mothers had cesarean section under general anesthesia (43.8\%), and 27 (56.3\%) had epidural anesthesia. Twenty two of the infants (45.8\%) were female and 26 (54.2\%) were males. The mean number of children was $1.98 \pm 0.91$, and the mean duration of pregnancy was $38.94 \pm 1.06$ weeks. The mean BDI score of mothers with a diagnosis of major depression was $34.26 \pm 22.80$.

There were no significant differences in terms of mean age, marital status, education level, socioeconomical level, number of children, gender of offspring, history of abortion, proportion of primiparity and type of the anesthesia between the groups. The cord blood BDNF level in infants of depressed and healthy mothers were $0.98 \pm 0.45$ $\mathrm{ng} / \mathrm{ml}, 2.08 \pm 0.91 \mathrm{ng} / \mathrm{ml}$ respectively. The difference between the groups was statistically significant $(t=-5.214$, $p=0.000$ ) (Table 1).

We didn't find any correlations between the cord blood BDNF levels and birth weight $(p=0.652)$, BDI score ( $p=0.487$ ), total duration of depression during pregnancy $(p=0.409)$, duration of pregnancy $(p=0.246)$ and number of children $(p=0.066)$ in depressed mothers.

\section{DISCUSSION}

In the present study, we found cord blood BDNF levels in infants of depressed mothers were significantly lower compared to infants of healthy mothers. To the best of our knowledge, this is the first study investigating the effects of depression during pregnancy on umbilical cord blood BDNF levels.

BDNF expression occurs in the earlier phases of fetal development, and contribute to the structural development of the cerebral cortex via its effect on cell migration. ${ }^{33)}$ Prenatal stress was reported to causea deteriorating effects on hippocampal cell proliferation during early phases of fetal development and decreased serum BDNF levels. Furthermore, Talge et al. ${ }^{30)}$ also found a positive correlation between cell proliferation and serum BDNF levels. Chan et al. ${ }^{34)}$ investigated prenatal and postnatal depletion of BDNF in mices. They found prenatal depletion of BDNF resulted in more pronounced depressive behaviours. Their results support the neurodevelopmental hypothesis of depression. Evaluating our data with previous literature points out that fetal cord BDNF level could be a possible biological marker of negative effects of emotional stress during pregnancy on the fetus.

In a mice study, BDNF has shown to cross from the placental barrier to the fetal blood circulation. ${ }^{19)}$ Combining our data with previous literature, it can be predicted that, low umbilical cord blood BDNF levels in infants of depressed mothers may be due to low blood levels of mothers. Supporting this prediction, we found, the umbilical cord blood BDNF levels in infants of depressed mothers were approximately twice as lower than infants of healthy mothers.

Only one study investigated BDNF levels in fetal cord blood. Uguz et al. ${ }^{22)}$ demonstrated that fetal cord BDNF levels were decreased in mothers with generalized anxiety disorder. Camkurt et al. ${ }^{1)}$ showed maternal depression was associated with decreased antioxidant activity in fetal cord blood. While evaluating our results in the light of previous data, we consider the investigation of biological parameters in fetal cord blood will be of importance to reveal neurodevelopmental basis for psychiatric disorders.

We didn't find any correlation between the umbilical cord blood BDNF levels and BDI scores and severity of depression. There are several studies investigating this correlation in non-perinatal period, however results are controversial. Although in a study, BDNF level was not found to be associated with the severity of depression, there are studies denoted a negative correlation between the severity of depression and BDNF levels. ${ }^{21,35,36)}$ These controversial results could be result from methodological issues.

The present study has several limitations, which may affect the interpretation of the results. First, the sample size was relatively small and included women who were admitted to the obstetric clinics for delivery. Therefore, it may not be representative of all pregnant women with depression. However, we screened patients for one year 
of time and we were able to found the current sample size. Second, the study had a cross-sectional design but not a prospective observation. For this reason, we did not determine course of severity of depression during pregnancy. Third, the sample is composed of women with elective cesarean only because to determine the cord blood samples in newborn of women who delivered vaginally was difficult in the clinics. However, this condition may be considered as a limitation. Finally, we collected blood samples only from umbilical vein. Future studies should include blood samples collected from both umbilical vein and the artery, and simultaneously from mothers to give a better picture of intreuterin environment in presence of maternal psychiatric disorder.

The study results suggest that the cord blood BDNF levels in infants of depressed mothers were significantly lower than infants of healthy mothers. As BDNF plays a role in neurodevelopment, decreased BDNF levels may be hypothesized to affect fetal neurodevelopment. For further studies, BDNF levels of infants should be widely investigated by researchers to identify a potential marker express in potential adverse effects of depression occurring during pregnancy. Thus, diagnosis and treatment of depression during pregnancy seems to be important for the neurodevelopment of the infant.

\section{REFERENCES}

1. Camkurt MA, Findıklı E, Bakacak M, Karaaslan MF, Tolun Fí, Tuman TC. Depression in pregnancy is associated with decreased glutathione peroxidase activity in fetal cord blood. I Psychiatr Res 2016;79:57-60.

2. Kitamura T, Yoshida K, Okano T, Kinoshita K, Hayashi M, Toyoda N, et al. Multicentre prospective study of perinatal depression in Japan: incidence and correlates of antenatal and postnatal depression. Arch Womens Ment Health 2006;9: 121-130.

3. Felice E, Saliba J, Grech V, Cox J. Prevalence rates and psychosocial characteristics associated with depression in pregnancy and postpartum in Maltese women. I Affect Disord 2004; 82:297-301.

4. Uguz F, Gezginc K, Kayhan F, Sari S, Büyüköz D. Is pregnancy associated with mood and anxiety disorders? A cross-sectional study. Gen Hosp Psychiatry 2010;32:213-215.

5. Camkurt MA, Findıklı E, Tolun FI, Bakacak M, Bal NG, Sakall 1 $\mathrm{H}$, et al. Probable preventive effects of placenta from oxidative stress; Evaluation of total antioxidant status, total oxidant status and oxidative stress index in fetal cord blood during the delivery. Psychiatry Res 2016;240:222-225.
6. Uguz F, Ayhan MG. Epidemiology and clinical features of obsessive-compulsive disorder during pregnancy and postpartum period: A review. J Mood Disord 2011;1:178-186.

7. Suri R, Altshuler L, Hellemann G, Burt VK, Aquino A, Mintz J. Effects of antenatal depression and antidepressant treatment on gestational age at birth and risk of preterm birth. Am J Psychiatry 2007; 164:1206-1213.

8. Grote NK, Bridge JA, Gavin AR, Melville JL, lyengar S, Katon WJ. A meta-analysis of depression during pregnancy and the risk of preterm birth, low birth weight, and intrauterine growth restriction. Arch Gen Psychiatry 2010;67:1012-1024.

9. Lewis AJ, Galbally M, Opie G, Buist A. Neonatal growth outcomes at birth and one month postpartum following in utero exposure to antidepressant medication. Aust NZJ Psychiatry 2010;44:482-487.

10. Davalos DB, Yadon CA, Tregellas HC. Untreated prenatal maternal depression and the potential risks to offspring: a review. Arch Womens Ment Health 2012;15:1-14.

11. Brunoni AR, Lopes M, Fregni F. A systematic review and meta-analysis of clinical studies on major depression and BDNF levels: implications for the role of neuroplasticity in depression. Int J Neuropsychopharmacol 2008;11:1169-1180.

12. Martinowich K, Manji H, Lu B. New insights into BDNF function in depression and anxiety. Nat Neurosci 2007;10:10891093.

13. Sözeri-Varma G, Enli Y, Aydın E, Toker-Uğurlu T, Alaçam H, Kalkan-Oğuzhanoğlu N. Relationship between serum BDNF levels and cognitive functions, cortisol levels in depressive disorder? J Mood Disord 2012;2:58-65.

14. McAllister AK, Lo DC, Katz LC. Neurotrophins regulate dendritic growth in developing visual cortex. Neuron 1995;15: 791-803.

15. Fossati P, Radtchenko A, Boyer P. Neuroplasticity: from MRI to depressive symptoms. Eur Neuropsychopharmacol 2004; 14 Supp/ 5:S503-S510.

16. Masi G, Brovedani P. The hippocampus, neurotrophic factors and depression: possible implications for the pharmacotherapy of depression. CNS Drugs 2011;25:913-931.

17. Rees S, Inder T. Fetal and neonatal origins of altered brain development. Early Hum Dev 2005;81:753-761.

18. Ansorge MS, Hen R, Gingrich JA. Neurodevelopmental origins of depressive disorders. Curr Opin Pharmacol 2007;7:817.

19. Kodomari I, Wada E, Nakamura S, Wada K. Maternal supply of BDNF to mouse fetal brain through the placenta. Neurochem Int 2009;54:95-8.

20. Chouthai NS, Sampers J, Desai N, Smith GM. Changes in neurotrophin levels in umbilical cord blood from infants with different gestational ages and clinical conditions. Pediatr Res 2003;53:965-969.

21. Karege F, Perret G, Bondolfi G, Schwald M, Bertschy G, Aubry JM. Decreased serum brain-derived neurotrophic factor levels in major depressed patients. Psychiatry Res 2002;109:143- 
148.

22. Uguz F, Sonmez EO, Sahingoz M, Gokmen Z, Basaran M, Gezginc K, et al. Maternal generalized anxiety disorder during pregnancy and fetal brain development: a comparative study on cord blood brain-derived neurotrophic factor levels. J Psychosom Res 2013;75:346-350.

23. Uguz F, Onder Sonmez E, Sahingoz M, Gokmen Z, Basaran $M$, Gezginc K, et al. Neuroinflammation in the fetus exposed to maternal obsessive-compulsive disorder during pregnancy: a comparative study on cord blood tumor necrosis factor-alpha levels. Compr Psychiatry 2014;55:861-865.

24. Camkurt MA, Findıklı E, İzci F, Kurutaş EB, Tuman TC. Evaluation of malondialdehyde, superoxide dismutase and catalase activity and their diagnostic value in drug naïve, first episode, non-smoker major depression patients and healthy controls. Psychiatry Res 2016;238:81-85.

25. Güneş M, Camkurt MA, Bulut M, Demir S, İbiloğlu AO, Kaya $\mathrm{MC}$, et al. Evaluation of paraoxonase, arylesterase and malondialdehyde levels in schizophrenia patients taking typical, atypical and combined antipsychotic treatment. Clin Psychopharmacol Neurosci 2016;14:345-350.

26. Findıklı E, Camkurt MA, İzci F, Karaaslan MF, Fındıklı HA, Sümer $\mathrm{P}$, et al. The diagnostic value of malondialdehyde, superoxide dismutase and catalase activity in drug naive, first episode, non-smoker generalized anxiety disorder patients. Clin Psychopharmacol Neurosci 2018;16:88-94.

27. Camkurt MA, Findıklı E, Bakacak M, Tolun Fİ, Karaaslan MF. Evaluation of malondialdehyde, superoxide dismutase and catalase activity in fetal cord blood of depressed mothers. Clin Psychopharmacol Neurosci 2017;15:35-39.

28. Gerardin P, Wendland J, Bodeau N, Galin A, Bialobos S, Tordjman S, et al. Depression during pregnancy: is the deve/- opmental impact earlier in boys? A prospective case-control study. J Clin Psychiatry 2011;72:378-387.

29. Van den Hove DL, Steinbusch HW, Scheepens A, Van de Berg WD, Kooiman LA, Boosten BJ, et al. Prenatal stress and neonatal rat brain development. Neuroscience 2006;137:145155.

30. Talge NM, Neal C, Glover V. Antenatal maternal stress and long-term effects on child neurodevelopment: how and why? J Child Psychol Psychiatry 2007;48:245-261.

31. First MB, Spitzer RL, Gibbon M, Williams JBW. Structured clinical interview for DSM-IV clinical version (SCID-I/CV). Washington, DC:American Psychiatric Association Publishing; 1997.

32. Beck AT, Epstein N, Brown G, Steer RA. An inventory for measuring clinical anxiety: psychometric properties. J Consult Clin Psychol 1988;56:893-897.

33. Fukumitsu $H$, Furukawa $Y$, Tsusaka M, Kinukawa $H$, Nitta A, Nomoto $\mathrm{H}$, et al. Simultaneous expression of brain-derived neurotrophic factor and neurotrophin-3 in Cajal-Retzius, subplate and ventricular progenitor cells during early development stages of the rat cerebral cortex. Neuroscience 1998; 84:115-127.

34. Chan JP, Unger TJ, Byrnes J, Rios M. Examination of behavioral deficits triggered by targeting Bdnf in fetal or postnatal brains of mice. Neuroscience 2006; 142:49-58.

35. Lee BH, Kim H, Park SH, Kim YK. Decreased plasma BDNF level in depressive patients. I Affect Disord 2007;101: 239-244.

36. Shimizu E, Hashimoto K, Okamura N, Koike K, Komatsu N, Kumakiri $\mathrm{C}$, et al. Alterations of serum levels of brain-derived neurotrophic factor (BDNF) in depressed patients with or without antidepressants. Biol Psychiatry 2003;54: 70-75. 